\title{
Students' and teachers' preferences in using different approaches and strategies in vocabulary teaching and learning
}

\author{
Seven Reshadova*
}

\begin{abstract}
Language teaching methodology has evolved over the years. The priorities in teaching English as a foreign language have changed and teaching vocabulary has gained importance as a result of a long process of research and experimentation. The article presents the results of two surveys conducted with the students of a control and an intervention class about their experience with different strategies used for learning new vocabulary. These results are mapped against the findings of a questionnaire among the teachers of the same school about the methods, strategies and, techniques and personal experience in teaching new vocabulary.
\end{abstract}

Key words: vocabulary, teaching, learning, strategies, preferences

\section{Introduction and background}

Second language education has changed immensely to meet the needs of modern society. People have become more mobile, and as a result have come into contact with foreign languages in their every-day life, which means that foreign language skills are a 'must' today. Therefore it is necessary to research and describe the most efficient ways to help students reach a certain level of second language proficiency, which will allow them to function successfully in a multi-lingual society.

Modern methodologies of teaching English as a foreign language offer an incredible array of approaches, strategies and techniques to teach vocabulary. The complexity of the possible ways to introduce new vocabulary and the importance of doing it well is often neglected and underestimated in foreign language teaching. Letting students struggle on their own with learning vocabulary is not an option in the modern classroom today, where the role of the teacher is becoming more active in the teaching/learning process. Working with the four language skills, teaching new lexis through a variety of strategies and techniques helps students encounter these lexical items repeatedly and offers them opportunities to understand the depths of the word knowledge, to explore and acquire the lexis of the language.

Intentional vocabulary teaching is of crucial importance for the effective language learning, but it was ignored for centuries in favor of grammar and syntax.

* BA student in the Department of English Studies, University of Shumen, Shumen, Bulgaria 
Having in mind that teachers usually teach relying on their own experience, it becomes easy to understand why it took so long to change the attitude towards vocabulary teaching. Opinions differ on the need for deliberate vocabulary teaching from 'there is no need to teach vocabulary directly', to 'the teacher has to offer different vocabulary activities and teach new words directly'. The change, that led vocabulary teaching to the position it has today, was not abrupt and revolutionary; it was a result of a long process, in which different modern methods have managed to change different aspects of traditional language teaching. Even when the focus fell on teaching words and their meaning, it took a long time to find the best ways to do that.

Nation (2008) suggests initial vocabulary teaching by using direct methods and strategies, and later changing the approach to more incidental and indirect teaching of vocabulary, thus allowing language learners to become more independent in their learning. The next thing to do is to teach students strategies and techniques to help them learn vocabulary on their own. A research among three hundred Sudanese learners suggests that the better learners apply and rely on different learning strategies and techniques (Coady, Huckin 1998).

Henricksen (1999) speaks of three dimensions in word knowledge. The basic level to be mastered at the first exposure to the vocabulary item is the word form (spelling) and its core meaning. Later exposures to the same word reveal more facets of its meaning, usage and derivations. Learning different aspects of lexis, such as frequency, collocation, register, case relations, underlying forms of a word, etc., is the second dimension in knowing a word. The third dimension is mastering receptive and productive vocabulary. The general opinion is that receptive vocabulary is acquired first and the productive afterwards, and that the first is always larger than the latter (Henricksen 1999 qtd. in Schmitt 2007). The goal of vocabulary study is to turn the receptive (passive) vocabulary into productive (active) vocabulary. Melka argues that "knowing a word is not an all-or-nothing proposition; some aspects may have become productive, while others remain at the receptive level" (Melka in Scmitt, McCarthy 2001:87). In terms of usage and retrieval, Nation (2002 qtd.) differentiates between receptive retrieval of vocabulary, when the form is perceived and the meaning has to be retrieved, and productive retrieval, when one wishes to communicate the meaning of the word and has to retrieve is spoken and written form.

Once the decision what vocabulary to be taught is made, the teacher should decide which approaches and techniques will be used to achieve the desired goals. The approaches can be direct or indirect depending to the way students get the knowledge about the words, and vary according to the emphasis they give to the context, instructions or classroom activities. As they complement each other, it is not necessary to choose one approach over the other ones, but rather to choose which approach is most suitable for the particular group of students and their level of language proficiency. Whereas the approaches are 
more general, the real tools the teacher works with in teaching vocabulary are strategies and techniques.

\section{Data analysis and discussion}

The article presents the results of two surveys conducted with the students of a control and an intervention class about their experience with different strategies used for learning new vocabulary. These results are mapped against the findings of a questionnaire among the teachers of the same school about the methods, strategies and, techniques and personal experience in teaching new vocabulary. The two 10th grade classes that took part in the survey are students from a Hauptschule - a secondary school in Germany, who study English twice a week. All of the students speak German as a first language but some of them have a second native language as well. The Control Class (Class A) consists of sixteen students, fourteen of whom are bilingual. This is a mixed group of students with diverse cultural backgrounds, which makes the work with them very interesting and productive. These young learners have affinity for English language learning, and their natural curiosity turns them into diligent learners. They monitor each other, correct each other's mistakes, and are always eager to learn more. All of them are used to intensive and extensive reading and independent work, each student has his or her own Oxford dictionary and often uses it to study words' meaning. In the lessons they are taught the target vocabulary and the teachers use Community Language Teaching as a method. The goals of this method are to motivate students to use effectively the language in communication and learn it while participating in dialogues and discussions. This is an experience-based method for which pair and group work is essential: something very suitable for the class, as the students get along very well with one another and have fun experimenting, and applying new methods in their work. These learners were chosen because they have already acquired some experience in using different strategies for learning vocabulary, which is relevant to the study. The teachers who answered the questionnaire have taught in all grades between 5 th and 10th.

\section{Students' preferences}

No matter what advantages and disadvantages different methods and strategies have, learners are the main factor in this process and they choose strategies that will facilitate their vocabulary knowledge acquisition. Each group of students is a different constellation of learners with a variety of preferences, abilities and level of word knowledge. Certainly there is an immense difference in teaching new words to a group that is motivated to learn English and to a group, which has to be motivated first. Sometimes a diversity of strategies is what keeps the students' interest high and makes the lesson productive, so different technical 
devices that help to present and practise vocabulary should be consistently used in the lesson. Sometimes achieving the results is satisfying enough, but if teachers try always to optimize the teaching process, the preferences, experience and personal affinities of the students towards different methods, strategies and techniques in teaching new words must be taken into consideration.

Before answering the questions in the survey, the learners in both classes did a reading comprehension task based on four articles, - interviews with different celebrities about what foreign languages they speak, a story about how a polyglot has learned seven languages, experts' opinions on how new words can be best learned. One part of the reading comprehension task is a questionnaire about their personal experience in learning new words. The reason why I decided to incorporate the questionnaire within the reading comprehension instead of giving it directly was the attempt to encourage the students first to think about the different strategies and techniques for learning new vocabulary, to confront them with the different aspects of the topic, to introduce some vocabulary related to this topic and then ask about their personal experience. The questionnaire consists of three parts: open questions, a list of eleven strategies, which the students have to rate according on their personal experience on the efficiency of each strategy and a question about their personal opinion about the best strategy to learn new words. The students had to rate eleven popular aids, which represent different strategies for introducing and teaching new vocabulary. The students had to rate the efficiency of these aids with useless-sufficient-satisfactory-useful and very useful, with the corresponding points. To evaluate the results it was enough to count the points that each aid got: useless -0 points, sufficient -1 point, satisfactory -2 points, useful -3 points and very useful -4 points. The results helped to create the diagram, that shows to what extent different aids are appreciated as efficient by the students.

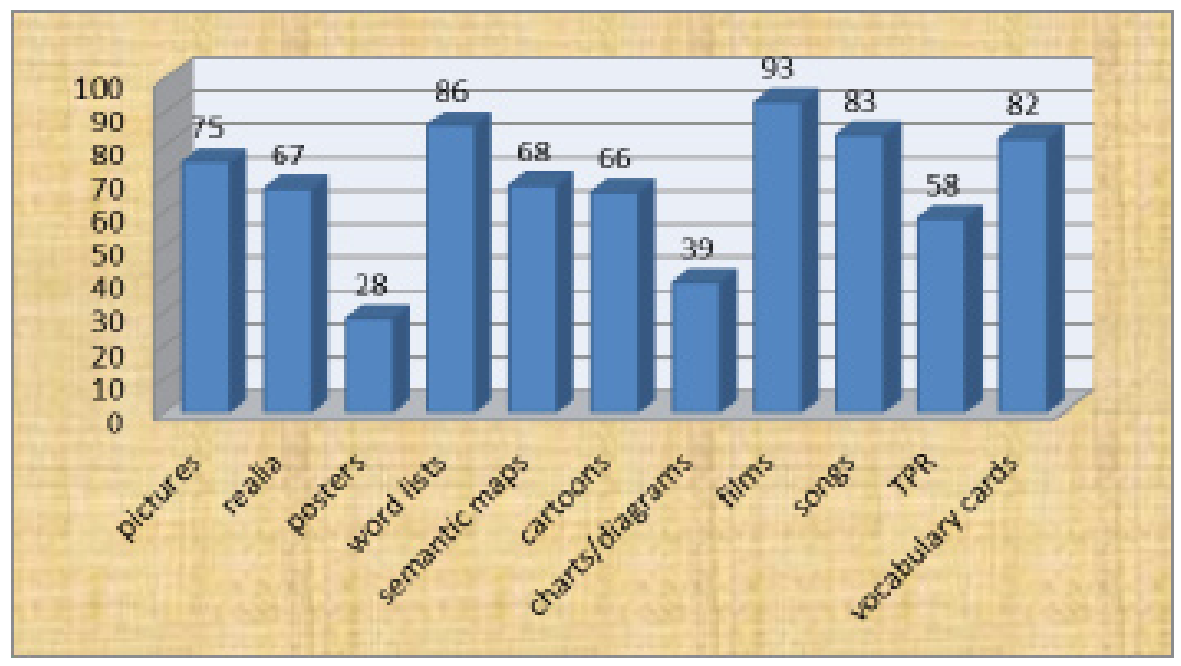

Fig. 1. Aids to teach new vocabulary 
The graph in Figure 1 shows that "Films" got the highest result for an aid to teach new words. A closer look at the answers shows that "Watching English Films" is described as the best strategy to learn new words by all 16 students, who answered the questionnaire. There are several important aspects that make this meta-cognitive strategy so useful according to the learners:

- Language plays a crucial role in understanding the sound and visual information that the film presents. The listening comprehension is supported by realia, actions, movements, mimes and gestures which makes the understanding of the language easier and guessing new words more successful.

- The subtitles facilitate comprehension when vocabulary knowledge turns out to be insufficient or listening comprehension skills fail. Both types of subtitles are described in the answers with their advantages: subtitles in English support the learners if they haven't heard the word right; subtitles in German are evaluated as more informative.

- The dialogues and plot of the film demonstrate the correct use of old and new words: correct/native speaker pronunciation, word choice according to the situation (difference between word choice in conversation between friends and formal conversation, for example, at work, with the boss, etc.), demonstration of certain grammar structures the words are part of (collocations, lexical chunks, etc.)

- Some students write that watching the same film several times facilitates their understanding of the language and the plot, and the repetition of the parts they have already understood helps learning the new words they contain.

- Watching English films is also pointed out as very productive for improving the listening skills in general.

- That Film Watching is fun is also given as an important factor. Students appreciate if a strategy can evoke and keep their interest and qualify it as motivating, - something teachers should always bear in mind.

The second best strategy according to the students" rating is the "Word Lists". There are two types of lists with new words: the ones made by the students in their notebooks and the ones in their textbooks.

- Students find it useful to write bilingual lists in their vocabulary notebooks - so they know what vocabulary to learn and review for the vocabulary tests later. 
- Other students prefer to learn from their Cornelsen text books in English, which include an appendix with a list of the unknown words from each unit, listed in the order of appearance, sometimes with additional pictures that support understanding the words, some information on the grammatical features that are important and an example sentence that demonstrates the word use.

The answers to the question whether they keep or not their own vocabulary notebooks provide more detailed information: $61 \%$ of the learners have admitted to having a personal vocabulary notebook, $53 \%$ of them state they use it actively and only $8 \%$ wrote they use it only now and then and not always write the new words in. A large number of the learners - 39\% admit they don't have a vocabulary notebook this year.

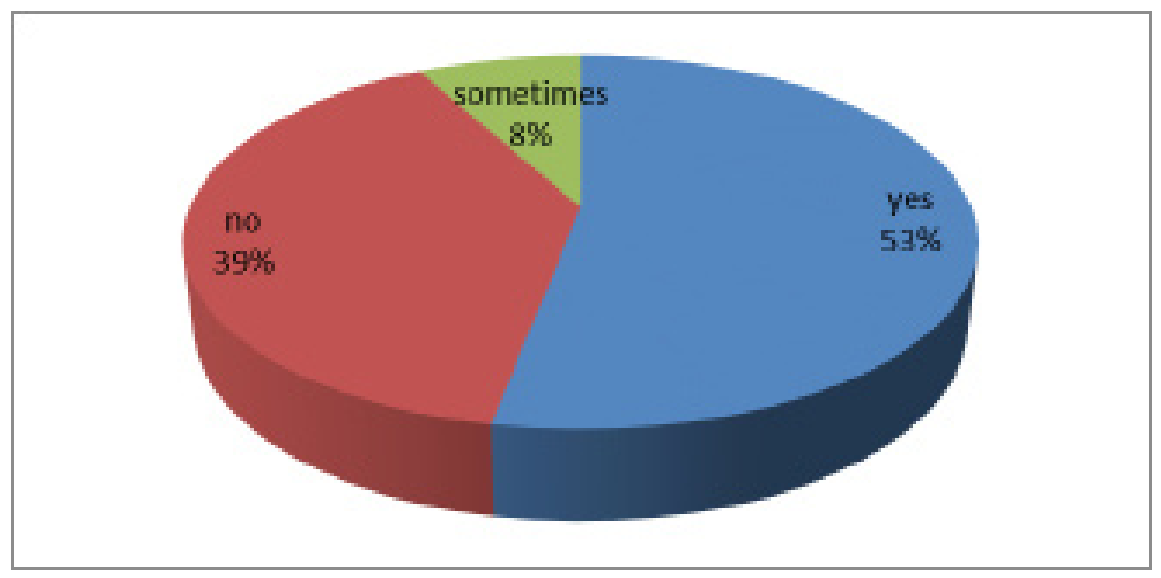

Fig. 2. Keeping vocabulary notebooks

Most surprising are perhaps the answers to the question whether the learners think that keeping vocabulary notebook helps in learning new words: $83 \%$ answered positively. Some of the learners write that they find it useful having vocabulary notebook to keep record of the new words, but they don't think it is necessary at this stage of their education - apparently they rely on the vocabulary in their text books in English and find it sufficient enough .

With the impressive rating of 83 points "Songs" took the third place. Learning English songs is a meta-cognitive device, which has proven its efficiency among the learners, and it is interesting to find out indeed that learners don't mind learning songs in the class. Moreover, they listen to songs on their own at home to broaden their vocabulary knowledge.

- They use the help of online dictionaries or dictionary books to determine the meaning of the unknown words. 
- The learning of the new words results from the repeated listening of the songs.

Close behind, with 82 points, is the technique of using "Vocabulary cards", on the fourth place. The students point out several features as an advantage:

- The easy access is described as its strongest advantage: students like having the cards always accessible in their school bags, so they can learn from them any time: on the way home or to school, in buses, while waiting in queues, etc.

- Most of the students write about bilingual cards: English word on the one side, the translation into German on the other side. Only few of them wrote about including example sentences.

- Some students write about learning together in groups using the cards. It is interesting how the learners in their attempt to become more successful in their learning, turn intuitively a simple memory strategy into a social one (learning new words together in a group) and by doing so increase its usefulness.

The fifth place takes "Pictures" with 75 points. The way Cornelsen Publishing designs their textbooks increases the role of pictures as a useful medium to learn/teach new words. The books are full of photos and drawings giving visual information about text content, and the vocabulary list includes pictures and drawings that help understanding word meaning and word retention. Teachers also use pictures while introducing new words (conclusion based on the observation done in both classes). The questionnaire doesn't include more information about the reasons and aspects why this strategy is so popular among the learners.

The strategy of using "Semantic maps" to learn new words is on the sixth place with 68 points. Judging by the semantic maps that the learners have done in their papers during the lesson "A Bad Dream" one can come to the conclusion that they have experience and enjoy creating them. Lots of old vocabulary on the topic was included right away, new words were written down along with the German translation, and some of the students have even made drawings showing the meaning of the new words as a part of the semantic map.

- The biggest advantage of learning through semantic maps is the combining of old words with new ones.

- The creation of the maps is seen as a brainstorming exercise to try to include as many words on the topic as the learners can.

- Doing semantic maps within a work group in class is pointed out as an interesting and entertaining way to make useful semantic 
maps. Students help each other and exchange word knowledge, and the results are obviously more satisfying for them.

Using "Realia" to learn new words received 67 points from the students. One of them described this strategy as his favorite one; and his advice was "Label everything in your room!". Apparently the learners have gained positive experience with this strategy.

Closely rated are "Cartoons" with 66 points. $23 \%$ of the students write about cartoons and comics as one of their favorite strategy to learn new words. "Important: find the methods that are fun for you; it's motivating you" wrote one of the learners. The Specificity of this strategy is that it is more popular among the boys than the girls. "Family Guy" is given as an example for favorite cartoon.

- Reading comics and watching cartoons is described as fun and a very useful strategy.

- Each cartoon or comic has its typical vocabulary which is easily remembered by watching it.

TPR has 58 points, and is ninth in the rating list. None of the students described it as a favorite strategy, so the answers don't contain any information about how students apply it and exactly which aspects of the strategy they find useful. Same is the situation with "Charts and Diagrams" that got 39 points, and the strategy of using "Posters" little surprisingly on the last place with only 28 points.

Something not included in the list was described as a favorite strategy by $34 \%$ of the learners: "Playing Video games". Important features of this strategy that learners find useful are:

- Character descriptions in English, which help learning different high frequency words that these descriptions include.

- Opportunity to repeat what they hear in the game: as an exercise to learn correct pronunciation of old and new words and as a device to learn new words through oral repetition.

- The online chat with native speakers was described as one of the most exciting aspects of using video games for learning English. Playing on an English server means meeting native speakers in the game chat.

- Voice chat was also described as an aspect that helps learning new words. Some learners describe that there is a great potential in learning English through speaking with native speakers, but it also demands some courage, because people are mostly shy and unsecure of their ability to understand native speakers. 
It was surprising to see how playing video games can be turned from a leisure activity into a successfully applied social strategy for learning new English words. Using the topic as a medium for conversation with native speakers and thus creating an interactive environment encourages the use of newly learned words and phrases and helps the retention of their meaning over time.

Another way to learn new vocabulary described by the learners is "Watching YouTube videos".

- Watch plenty of videos on one topic: a strategy similar to narrow reading, where the learners read different texts on the same topic over a period of time in order to learn the vocabulary typical for this topic.

- Theopportunitytowatcheveryvideountilthelearnerunderstands each word in it, takes away the tension, that something can be missed and the meaning can be misunderstood,.

- Watching YouTube videos is described as facilitating listening skills: understanding becomes easier with the time.

- Vocabulary knowledge on the topic increases.

- Learners say they pay attention to the way sentences are build, not only the words they include. (collocations and lexical chunks are learned this way)

Another aspect of learning new words that was assessed through the questionnaire was whether students use oral and written repetition and to what extent. 53 $\%$ of them say they use both types. Descriptions of the process are mostly following the same pattern, a new word is written down five times and every time is repeated aloud. Oral repetition is also used in the work with vocabulary notebooks - students read and repeat aloud the words they want to learn or have forgotten.

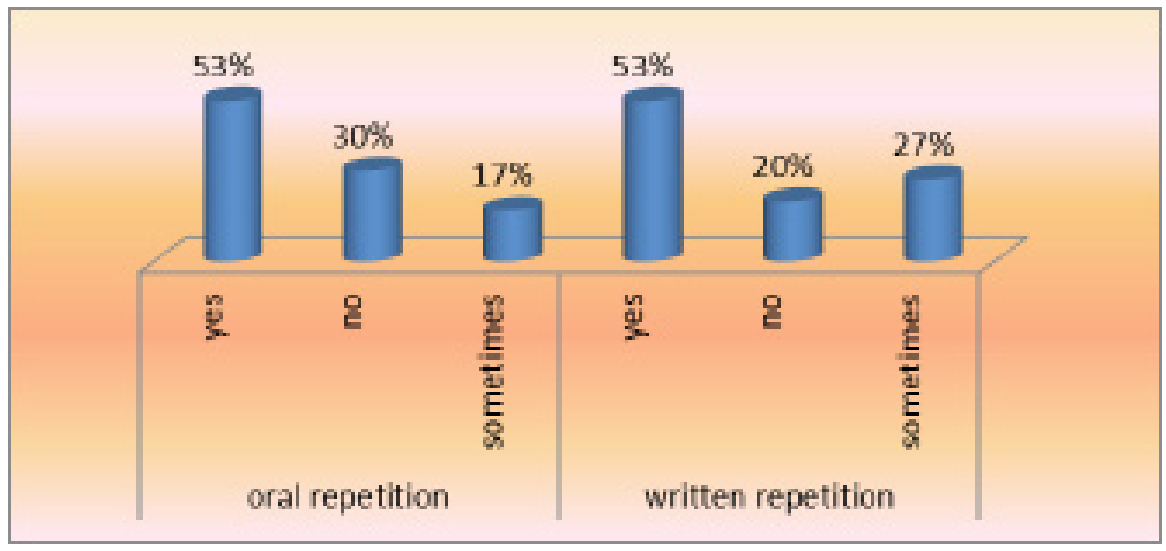

Fig. 3. Use of oral and written repetition 
We can see that these memory strategies of mechanical repetition are still something students rely on, along with the more modern ones, which were already described.

\section{Teachers' preferences}

The methods and strategies teachers use in teaching new vocabulary can facilitate or restrain students' learning skills and play significant role when learners model their learning style. Analysis of a questionnaire among ten teachers in English, with different years of experience (between 4 and 15) in teaching students of all grades from fifth and tenth, aims to picture the principles they follow in their work with the learners. The questionnaire includes nine yes/ no questions and two open questions. All of the questions concern different strategies and techniques to introduce and teach new words. The teachers were supposed to answer if they use or not particular teaching devices and also to rate each strategy according to the efficiency it has had with their students giving points from one to five, where one means it is useful for few students and five it is useful for all of their students.

The first impression from the questionnaire is that teachers apply different devices, even those they didn't rate as efficient for all of the students. Apparently they don't just aim high efficiency with the class as a whole but apply different strategies and methods to introduce and teach new words giving learners the opportunity to model their learning style or just try something different.

Teachers were asked about their opinion on the usefulness of having vocabulary notebook to keep track of new words. All of them answered positively to the question whether the learners have vocabulary notebooks and whether it is useful for them to write down the new words that are introduced in class. The efficiency of keeping track of the newly learned words this way is appreciated as better than using the vocabulary in the textbooks.

$70 \%$ of the teachers find the mechanical strategies such as oral or written repetition useful for over $90 \%$ of the students. This corresponds to the results from the questionnaire with the students where they describe the traditional way to learn a new word by writing it several times, reading it aloud and putting it down in the vocabulary notebook for later revision as the way they use for learning the new words at home. $30 \%$ of the teachers don't think a mechanical memory strategy as repetition (oral or written) is very useful for word retention. 


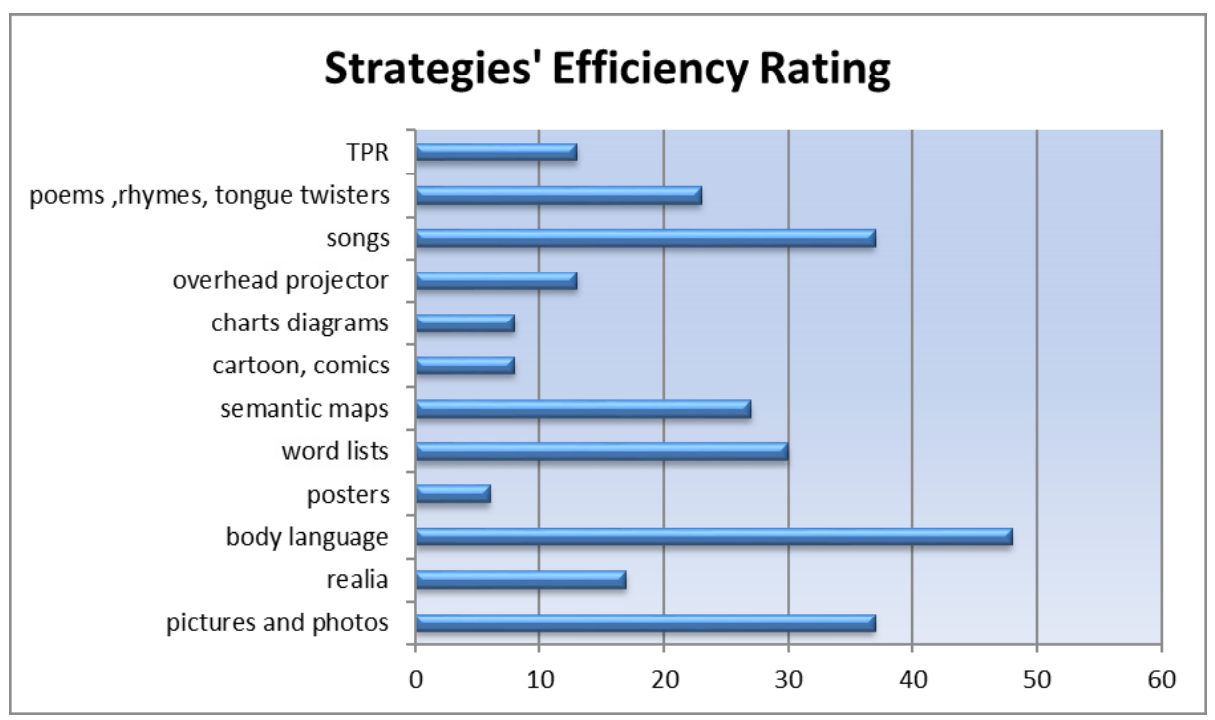

Fig. 4. Strategies' efficiency

For the evaluation of the results I used the same instrument, simply summing up the points which teachers gave each strategy for its efficiency.

- "Gestures, mimes and body language" got the impressive score of 48 points, proving to be popular, efficient and an inseparable part of the process of introducing new words.

- The strategy "Songs" got a reasonably high score of 37 points for its efficiency. The students have also scored this strategy high. "Songs" share the second place with "Pictures and Photos". Having in mind what opportunities this device offers and that the textbooks include plenty of pictures and photos it is no surprise that this strategy is so highly rated.

- Some of the teachers have evaluated semantic maps with the highest score, others gave them only few points, so the overall rating is 27 points, which puts it in a third place. As this strategy would only be useful in the classes where students have more advanced word knowledge, this might be the reason why it is not considered equally useful to all students. According to my observations, students have fun making semantic maps; they try to create them individually, use additional techniques such as drawings, combining words in pairs of antonyms or synonyms, classifying them, etc. Creating semantic maps is a device that not all teachers value enough but which is, on the contrary, highly appreciated by students. The question whether students 
use semantic maps as a learning device, half of the teachers answered with "no". It can be seen as a missed opportunity to increase the efficiency of introducing new words in a way preferred by the learners.

- Realia, which got 17 points, is a strategy used by half of the teachers. It is followed by TPR (13 point) which is also not very popular among the teachers. Overhead projector got the same amount of 13 points. The school offers use of overhead projector in every class room, so apparently it is not a choice resulting from the lack of technical support.

- Most surprisingly a strategy which was highly rated by the students got very few points from the teachers: "Cartoons and Comics" share the same result of eight points with "Charts and Diagrams". As far as "Charts and Diagrams" are concerned, they are not preferred by students as well.

- As well as by the students, the teachers evaluated "Posters" as the least useful strategy. It got the last place in the rating list with only 8 points.

It is important to point out that if teachers don't introduce a particular strategy, students won't have the opportunity to test its efficiency. Strategies like using posters, charts and diagrams, TPR and realia are not very popular among teachers and students. The question is whether students ignore some strategies because the teachers didn't teach them how to use them, or whether the teachers avoid these strategies because they know these will not prove as useful. Further research can give answers to these questions.

There are different questions concerning the sources that serve as a medium for introducing new words. Authentic materials such as articles and advertisements from magazines or newspapers are used by only $30 \%$ of the teachers and they give them maximum points for efficiency. Only half of the teachers find it useful to tell a personal story or an anecdote while introducing or teaching vocabulary. The ones that used this strategy rated it as a very useful one. Only few teachers use texts on topics, interesting for the students and they don't find it useful for all students. Longer working with the same topic in order to give students the opportunity to come across words typical for the topic, is rated as not very efficient. Extensive reading is also not very popular among the teachers, as it requires additional class time for presentations or discussions. On the whole, reading strategies were surprisingly low rated. Communicative strategies such as pair and group work got 46 from the possible 50 points. Teachers find them very useful for practicing and consolidating vocabulary. These strategies have also proven their efficiency in the lesson observation, where the students in the 
communicative lesson, showed high interest, were motivated and participated actively.

Another important aspect in teaching English vocabulary is the use of German language in the lessons. $20 \%$ of the teachers claim that they don't use it at all, while the other $80 \%$ confirm the use of German language and evaluate it as very useful for more than the half of the students. The answers to the question about how students can be motivated best to learn new words, there was a variety of answers: activities that include dialogues, pair work, rhythm talk, stories, use of vocabulary flash cards, vocabulary games, riddles, puzzles, four corners guessing, etc. According to the answers of the questionnaire the teachers use besides the strategies that have proven to be useful and efficient, new strategies as well which they find very efficient. Trying out a new strategy got from four or five points for efficiency from all teachers, which proves how important the variety of methods and strategies in teaching is. Having in mind that in each classroom the teacher has a computer with Internet access and a smart board (interactive white board), it is not surprising that all of the teachers wrote that they use the Internet as a source of texts, videos, songs, etc. in teaching new vocabulary. Both students and teachers benefit from the advantages offered by technical equipment, which makes the lesson informative, dynamic and keeps the students engaged.

\section{Conclusions}

Teaching English vocabulary is not only about applying a particular method, approach or strategy, it is a process in which both partners, the teacher and the learner, play an important role. Students' with their expectations, preferences and knowledge, and teachers with their opinion and experience are the two sides of an interactive and dynamic partnership. The process can be successful only if there is a dialogue between the participants, if the teacher meets the needs of the learners by choosing the best way to introduce new knowledge.

In terms of strategy efficiency, students gave preference to strategies related to extensive vocabulary practice, such as films and songs, on the one hand, and intensive practice by means of word lists and vocabulary cards. The least preferred strategies involved the use of TPR activities (in part due to students' age) and other visuals, such as charts, diagrams and posters. As for keeping a systematic written record of studied vocabulary, only more than half of the students keep vocabulary books, although 83 percent think that having a vocabulary book helps learning new words. Only about half of all students think that writing the new words a number of times and doing oral drills help them learn better.

Teachers admit to using a variety of strategies, even if they don't fully believe 
in their efficiency. In assessing strategy efficiency they gave preference to using body language, songs, pictures and photos, as well as word lists and semantic maps. The least popular ones were charts, diagrams, posters, and, contrary to students' preferences - cartoons and comics.

There are parallels between the two questionnaires that allow us to realize how different sometimes the opinions of students and teachers are on how students best learn new words. It is essential to avoid such discrepancies and the solution is to talk about them openly and try to find a solution which suits both learners and teachers. Cartoons and comics for example turned out to be one of the most popular learning devices among students but, on the contrary, teachers don't have high opinion of the efficiency of this device. Students' interest makes comics and cartoons efficient as a device, which means that they should be used more in class activities to support the learning process and facilitate word acquisition and retention. While some teachers rate a strategy with maximum points as useful for all students, others don't apply it at all; it is striking how different and unique the teaching styles can be. Modern views on teaching vocabulary are sometimes combined with more traditional ones. Perhaps there is no right or wrong way of choosing a method or a particular strategy for teaching words; what counts is its efficiency, and it is up to the teacher to understand what students will most benefit from.

Unfortunately, efficient teaching does not necessarily lead to successful learning. It is therefore essential that the teachers endeavor to find the most suitable and efficient devices to teach a particular group of learners. The survey with the teachers showed that their choice of strategies affects and to a certain extent even models students' learning styles. The question is whether students ignore some strategies because the teachers didn't teach them how to use them, or whether the teachers avoid these strategies because they know they will not be useful. Further research can give answers to these questions. But the problem is that if teachers avoid using certain strategies, they will be depriving students of potentially valuable ways of learning. Students have become more demanding and critical towards the way knowledge is presented, and they want to participate in the lessons, to experience the language, to see how it functions. Some of the traditional strategies have kept their role in teaching vocabulary supporting a whole range of new strategies and devices. A completely new era of smart boards, internet and media use has changed the educational frames. Modern society offers an open, unrestricted access to a vast variety of English language media: newspapers, magazines, music, films, books, advertising, television and Internet - something which has influenced education immensely, made learners more self-reliant and brought learning English outside the boundaries of the classroom. 


\section{References}

Coady, Huckin 1998. Coady J., Th. Huckin. Second Language Vocabulary Acquisition. Cambridge University Press, 1998.

Henriksen 1999. Henriksen B. Three Dimensions of Vocabulary Development. Studies in Second Language Acquisition, 21. 1999. 303-317.

Melka 1997. Melka F. (1997). "Receptive vs. Productive Aspects of Vocabulary". In Schmitt N., M. McCarthy (Eds.). Vocabulary Description, Acquisition and Pedagogy. Cambridge University Press, 2001. 84-102.

Nation 2002. Nation I. S. P. Learning Vocabulary in Another Language. Cambridge University Press, 2002.

Nation 2008. Nation I.S.P. Teaching Vocabulary. Strategies and Techniques. Heinle. Cengage Learningan, 2008.

Schmitt 2007. Schmitt N. Vocabulary in Language Teaching. Cambridge University Press, 2007.

Schmitt, McCarthy 2001. Schmitt N., M. McCarthy. Vocabulary Description, Acquisition and Pedagogy. Cambridge University Press, 2001. 